\title{
JUICIO MORAL DE ESTUDIANTES Y MAESTROS ANTE HECHOS DE VIOLENCIA EN UNA ESCUELA SECUNDARIA PÚBLICA EN MÉXICO
}

\author{
Myriam Fracchia Figueiredo ${ }^{1}$ \\ ${ }^{1}$ Doctora en Ciencias Sociales (UAM-Xochimilco, México). Investigadora colaboradora en el Proyecto "Programa de Cultura \\ de Paz y Noviolencia: Alternativas de aprendizaje y transformación de las violencias", Facultad de Filosofía y Letras, \\ Universidad Nacional Autónoma de México. ORCID iD: https://orcid.org/0000-0002-3279-7857 E-mail: \\ myrfracchia@gmail.com
}

\section{RESUMEN}

La investigación sobre los hechos violentos en los ámbitos cotidianos de los estudiantes de una escuela secundaria en México tuvo como objetivo develarlos como parte de un proceso formativo a sus maestros. Desde la concepción de que la violencia social y escolar son inherentes al orden social y se expresan en los cuerpos y en las cosas, nuestro abordaje interdisciplinario, se basó en una metodología mixta, utilizando técnicas cualitativas, a través de la observación, la planificación pedagógica, la reflexión común y la evaluación con los docentes y, técnicas cuantitativas, con la elaboración y aplicación de una entrevista de los docentes a 429 estudiantes de los tres grados de secundaria, en los turnos matutino y vespertino, para relevar el entramado de violencia, con énfasis en la escuela, y la posterior conformación de una base de datos para su sistematización y análisis. Esta estrategia metodológica permitió desentrañar el juicio moral de los estudiantes y de los adultos en correspondencia con los hechos de violencia vividos por los estudiantes, que han sido sobre todo peleas y golpes, acoso y robo. Las intervenciones al respecto de los adultos, acordes a la normatividad escolar, ha sido la aplicación predominante de sanciones expiatorias, o su inacción, sumando así otras formas de violencia que expresan un juicio moral heterónomo. Esto obliga a la mayoría de los estudiantes a cuidarse de no caer en provocaciones por parte del otro grupo minoritario, dispuesto a atacarlos como forma de dirimir sus diferencias. También el juicio moral de los estudiantes es heterónomo y sus propuestas para enfrentar estos hechos, en gran parte, coinciden con la normatividad escolar. Sin embargo, un grupo minoritario de estudiantes propuso además, la escucha, la empatía y el diálogo, que se "favorezcan comportamientos propios entre iguales", que es la ley de la verdadera cooperación, sugerente para un proceso formativo de los adultos que facilite la transición hacia un juicio moral de cooperación, para una convivencia de protección y mejor proceso de enseñanza-aprendizaje.

Palabras clave: Violencia; Juicio mora; Estudiantes de secundaria; Sanciones; México

\section{MORAL TRIAL OF STUDENTS AND TEACHERS BEFORE ACTS OF VIOLENCE IN A PUBLIC SECONDARY SCHOOL IN MEXICO}

\section{ABSTRACT}

The objective of the investigation into the violent events in the daily environments of the students of a secondary school in Mexico was to reveal them as part of a training process for their teachers. From the conception that social and school violence are inherent to the social order and are expressed in bodies and things, our interdisciplinary approach was based on a mixed methodology, using qualitative techniques, through observation, pedagogical planning, common reflection and evaluation with teachers, and quantitative techniques, with the preparation and application of an interview of teachers to 429 students of the three grades of secondary school, in the morning and evening shifts, to relieve the network of violence, with emphasis on the school, and the subsequent creation of a database for its systematization and analysis. This 
methodological strategy made it possible to unravel the moral judgment of students and adults in correspondence with the acts of violence experienced by the students, which have been mainly fights and beatings, harassment and robbery. Interventions regarding adults, in accordance with school regulations, have been the predominant application of expiatory sanctions, or their inaction, thus adding other forms of violence that express a heteronomous moral judgment. This forces the majority of students to be careful not to fall into provocations from the other minority group, ready to attack them as a way to settle their differences. Also the moral judgment of the students is heteronomous and their proposals to face these facts, to a large extent, coincide with the school regulations. However, a minority group of students proposed, in addition to listening, empathy and dialogue, that they "favor their own behaviors among equals", which is the law of true cooperation, suggestive for a formative process of adults that facilitates the transition towards a moral judgment of cooperation, for a coexistence of protection and a better teaching-learning process.

Keywords: Violence. Moral judgment. Secondary students. Sanctions. Mexico.

\section{JULGAMENTO MORAL DE ALUNOS E PROFESSORES MEDIANTE ATOS DE VIOLÊNCIA EM ESCOLA SECUNDÁRIA PÚBLICA DO MÉXICO}

\section{RESUMO}

O objetivo da investigação sobre os acontecimentos violentos no cotidiano dos alunos de uma escola secundária no México foi revelá-los como parte de um processo de formação de seus professores. Partindo da concepção de que a violência social e escolar são inerentes à ordem social e se expressam em corpos e coisas, nossa abordagem interdisciplinar baseou-se em uma metodologia mista, utilizando técnicas qualitativas, por meio da observação, do planejamento pedagógico, reflexão comum e avaliação com professores, e técnicas quantitativas, com a elaboração e aplicação de entrevista de professores a 429 alunos das três séries do ensino médio, nos turnos matutino e noturno, para alívio da rede de violência, com ênfase na escola, e a posterior criação de um banco de dados para sua sistematização e análise. Essa estratégia metodológica possibilitou desvendar o julgamento moral de alunos e adultos em correspondência com os atos de violência vivenciados pelos alunos, que foram principalmente brigas e espancamentos, assédios e roubos. As intervenções em relação aos adultos, de acordo com a regulamentação escolar, têm sido a aplicação predominante de sanções expiatórias, ou sua inação, agregando-se outras formas de violência que expressam um julgamento moral heterônomo. Isso obriga a maioria dos alunos a ter cuidado para não cair em provocações do outro grupo minoritário, pronto para atacá-los como forma de resolver suas diferenças. Também o julgamento moral dos alunos é heterônomo e suas propostas para enfrentar esses fatos, em grande medida, coincidem com os regulamentos da escola. Porém, um grupo minoritário de alunos propôs, além da escuta, da empatia e do diálogo, que "favoreçam seus próprios comportamentos entre iguais", que é a lei da verdadeira cooperação, sugestiva de um processo formativo de adultos que facilite o transição para um juízo moral de cooperação, para uma coexistência de proteção e um melhor processo de ensino-aprendizagem.

Palavras-chave: Violência. Julgamento moral. Alunos do Ensino Médio. Sanções. México.

\section{INTRODUCCIÓN}

Esta investigación exploratoria se ha realizado en el contexto de una intensa violencia social en México, que ha sido creciente por lo menos desde 2006, con el anuncio de la "guerra contra el narcotráfico" efectuado por el entonces presidente Felipe Calderón, con la resultante actual de casi 300 mil muertos, más de 60 mil desaparecidos y más de tres mil fosas clandestinas en todo el país. ¿De qué manera se expresa la relación entre este proceso y los que se desarrollan en los planteles escolares y qué efectos tienen en los estudiantes de secundaria?

En el marco de un diplomado de formación docente con G. Poujol, en 2016, que tuvo como objetivo dotar a los maestros de habilidades para el desarrollo de investigación e intervención con el fin de mejorar la convivencia escolar, hemos llevado a cabo, el estudio exploratorio de hechos de violencia en los ámbitos cotidianos de los 
estudiantes de una secundaria pública de Cuernavaca, en Morelos (México), ubicada en una de las zonas de mayor conflictividad (POUJOL; FRACCHIA, 2017).

Esta investigación aporta una perspectiva teórica-metodológica y hallazgos que permiten reconocer en los cuerpos de los estudiantes observados el conjunto de hechos de violencia de los que son objeto, así como del juicio moral que al respecto ellos y los maestros tienen, que explica las formas en que los adultos intervienen y las propuestas para enfrentarlos. A su vez este conocimiento contribuye a realizar intervenciones multidisciplinarias con el fin de lograr la protección de la comunidad escolar.

\section{ABORDAJE TEÓRICO- METODOLÓGICO DE LA INVESTIGACIÓN EXPLORATORIA}

Consideramos la violencia como una dimensión constitutiva del orden social en cuanto supone un instrumento en el ejercicio de la instauración y la permanencia del poder (KLOSTER; FRACCHIA, 2017), siendo los cuerpos y las cosas, sus soportes materiales 0 mediaciones (MARÍN,1995), en un espacio y tiempo determinados. Desde la perspectiva genética que asumimos (PIAGET, 1975, p. 173), esta relación entre contexto y cuerpo presupone una relación inseparable entre psicogénesis y sociogénesis, es decir, entre las estructuras psicológicas individuales y las estructuras sociales: desde la relación entre dos individuos "hasta la totalidad constituida por el conjunto", en este caso, de los ámbitos sociales del cotidiano de los estudiantes observados desde la escuela objeto de estudio, que "produce nuevos caracteres que transforman al individuo en su estructura mental." (p.161). En esas relaciones en que los individuos "se modifican, se forman y transforman constantemente", cada uno ocupa una posición y desarrolla funciones que se hallan en interrelación con las de los demás individuos, dentro de un "entramado" o "red de interdependencias" (ELIAS, 1989, p. 12), como lo iremos señalando en los hallazgos.

La perspectiva genética seleccionada tiene correspondencia con el estructuralismo genético de Bourdieu y Passeron (1977, apud GUTIÉRREZ, 2004) que distinguen la violencia estructural, o el conjunto de posiciones y funciones de los individuos en el entramado de relaciones sociales desiguales, teñidas de poder, que obtienen "la obediencia al orden social establecido" (BOURDIEU, apud GARCÍA, 2012, p. 119) y que se expresan físicamente, de la violencia simbólica, que conciben como "todo poder que logra imponer significaciones e imponerlas como legítimas" (GUTIÉRREZ,2004, p. 289), interiorizados en los cuerpos que así aplican "unas estructuras de percepción que a su vez sean las mismas que las que emplea el dominante para producir" su dominio (BOURDIEU, apud GARCÍA,2012, p. 131)

La contribución de estos autores es sumamente interesante en cuanto no les interesa el estudio de los hechos violentos en sí, ni su tipología sino las formas en que éstos influyen "en las estrategias de reproducción social, que los individuos y los grupos operan para establecer, conservar o transformar el orden establecido" (GARCÍA, 2012, p. 123), lo que también se reproduce en el ámbito escolar que consideran como un "espacio privilegiado de la reproducción de la estructura de las relaciones de fuerza entre las clases"(GUTIÉRREZ, 2004, p. 296), y proponen que para escapar de las acciones de violencia simbólica es necesario, conocer o realizar "una toma de conciencia de lo arbitrario" que es impuesto (GUTIÉRREZ, 2004, p. 298).

Para el conjunto de autores considerados, el observable central de una relación social es la acción. En su investigación sobre El criterio moral en el niño (PIAGET,1985), Piaget analiza la correspondencia entre ésta y la representación de la misma (o conciencia), distinguiendo fases progresivas del juicio moral, considerando un primer estadio en donde el sujeto no se distingue del medio social y no tiene conciencia acerca de la acción propia ni la de los otros y un segundo estadio, el del egocentrismo, caracterizada por la heteronomía, que es en donde hemos hallado que se sitúa el juicio moral en el entramado de la escuela en estudio, coincidente a la vez con el estadio social actual predominante: "el dominio del capitalismo y de una teoría del dominio capitalistadebía asentarse en la perdurabilidad de este segundo estadio en la construcción del juicio moral" (MARÍN, 1995, p. 20).

En esta fase del juicio moral, el individuo adquiere conciencia de sí mismo y del otro, pero desde su dependencia de los adultos o autoridad; el sistema normativo (como leyes, reglamentos, 
instrucciones, instituciones) que dicta un comportamiento como el que "debe de ser" y que trae aparejada una noción de justicia retributiva, que justifica el castigo o sanción, para quien no obedece 0 no sigue dichas normas de comportamiento estipuladas. La sanción, a su vez, puede ser de dos tipos: la sanción expiatoria, que no considera la proporción entre castigo y la "falta" cometida e incluso sostiene que, a mayor dolor infligido, mayor será la obediencia a obtener y la "sanción por reciprocidad", que guarda relación entre la falta y su reparación, al tomar en cuenta las condiciones en que se ha originado y la intencionalidad de los individuos, que se acerca a las siguientes fases.

El tercer y cuarto estadios del juicio moral, los de la cooperación, inician, según Piaget (1985), cuando el sujeto empieza a descentrarse, a cuestionar el sistema normativo que conoce y obedece; toma conciencia de que ése es fruto de una construcción humana y que por tanto, se puede deconstruir; está en condiciones de preguntarse acerca de su pertinencia y de empezar a diferenciarse del mismo e incluso, es capaz de pensar en alternativas al mismo; descubre la fuerza de la acción y del pensamiento colectivos, el juicio moral se hace autónomo; surge la posibilidad de cooperación, de solidaridad entre iguales. Estas fases traen aparejadas la noción de una justicia distributiva, en busca de la igualdad e incluso de equidad, por lo que ante una "falta" de solidaridad con el grupo del que se es parte, no se recurre a ninguna sanción para enfrentarlo sino al diálogo y al acuerdo mutuo para reparar la afrenta grupal, como el instrumento de resolución o de reparación de la misma.

Es así, que tanto en el ámbito social como en el psicológico hay estadios del juicio moral que dictan nuestros comportamientos $y$ representaciones de la realidad. Es posible realizar procesos de ruptura epistémica para pasar de un estadio a otro. Es ahí donde creemos en el poder de una intervención psicopedagógica y social para crear las condiciones de pasaje desde el egocentrismo y su correspondiente juicio moral heterónomo hacia la cooperación e incluso la equidad en correspondencia con un juicio autónomo, capaz de generar de común acuerdo, normatividades acordes a la realidad específica que se vive en los ámbitos escolares y que propicien mejores relaciones sociales, más igualitarias, y ojalá, desde una lógica de equidad. Y que, como primer paso, requieren ser conocidas las condiciones socioescolares de heteronomía con los instrumentos de la investigación, necesarios de ser fortalecidos en la formación docente.

Respecto a nuestra postura también en torno al debate acerca de la denominada violencia escolar - "concepto polisémico, multidimensional y complejo, por lo que no hay acuerdos entre los investigadores acerca de cómo definirlo" (SAUCEDO; GUZMÁN, 2018, p. 226-227), adscribimos a la vertiente que advierte acerca de la correspondencia que tiene con el de violencia social, apuntado más arriba, por lo que la violencia escolar es expresión del orden social existente y "se refieren a aquellas acciones tendientes a buscar el control del otro y su sometimiento, que revisten diferentes formas con diferentes efectos en las relaciones sociales que involucra-ya sean alumnos, padres, profesores o personal subalterno - que pueden producirse en espacios relacionados a la escuela". En consonancia con diversos autores como Spósito (1998, p. 60); Maldonado (2004, p. 5); Castillo y Pacheco (2008), entre otros (citados en OVIEDO; FRACCHIA, 2018).

Esta perspectiva es más amplia o incluso divergente de aquella que se remite al aporte del noruego (OLWEUS, 1998) para quien la violencia es una conducta agresiva en la que el actor o perpetrador usa su cuerpo o un objeto (incluyendo armas) para infligir daño (relativamente serio) o molestia a otro individuo o los que consideran que la violencia en la escuela se produce cuando existen actos intencionales que provocan daño o amenaza, los cuales van ligados al abuso del poder por parte de los individuos más fuertes en contra de otros más débiles (OVIEDO; FRACCHIA, 2018).

Cabe aclarar que el debate sobre la violencia escolar en México se ha desplazado, en una primera etapa, del estudio de la indisciplina escolar al del de la violencia escolar y de éste hacia el de la convivencia, actualmente (FURLÁN, 2003 y 2013; LÓPEZ; SAÑUDO; MAGGI, 2013; SAUCEDO; GUZMÁN, 2018). Personalmente creo que desde esta perspectiva es imposible no tratar la violencia escolar como una de las formas de convivencia existentes, constituyendo su diagnóstico el punto de partida para lograr su modificación. 
La perspectiva genética asumida-de interrelación inseparable entre socio y psicogénesis es la que permite estudiar el proceso constituyente de los hechos, en el caso de nuestro estudio, de violencia de los estudiantes de secundaria, que emanan de sus relaciones sociales en diferentes ámbitos de su cotidiano y de las relaciones que también guardan éstos entre sí, que se expresan en sus cuerpos, como la materialización de una condensación de relaciones sociales e influyen en las representaciones, diría Bourdieu o en la toma de conciencia o juicio moral, diría Piaget, que los estudiantes tienen de los mismos y de la de los adultos que con ellos conviven.

Nuestro abordaje es interdisciplinario en cuanto involucra la sociología, la psicología, la pedagogía e incluso la estadística porque se trata de una metodología mixta, basada tanto en técnicas cualitativas, que han propiciado un proceso de formación docente, a través de la observación, la planificación pedagógica, la reflexión común, el proceso de investigación y la evaluación; como técnicas cuantitativas, con la elaboración de una entrevista con el fin de captar el entramado de los diversos ámbitos cotidianos del estudiante, con énfasis en la escuela. Las dimensiones tomadas en cuenta fueron algunas características sociodemográficas de los estudiantes (edad, sexo) y escolares (grado, turno) así como sociales (colonia de residencia) y el eje que los ha atravesado han sido los hechos de violencia existentes en su colonia, en su familia, en la escuela en general y en su aula, así como la descripción de los efectos que hayan tenido sobre ellos y más específicamente, en el ámbito escolar: la forma en que los adultos enfrentaban los hechos de violencia escolar, su juicio moral al respecto y sus propuestas para resolverlos, en contraste con las de los estudiantes.

Después de vencer las resistencias que inicialmente tuvieron los adultos de la institución hacia este instrumento, con el argumento de que no se obtendrían respuestas al respecto porque los estudiantes habían normalizado y naturalizado las distintas formas de violencia existentes, de los 32 maestros participantes en el diplomado, 20 lo aplicaron a su grupo de estudiantes, con la resultante que se abarcaron los tres grados de secundaria, en el turno matutino y en el turno vespertino, en partes iguales, a un total de 429 estudiantes, que aproximadamente representó la mitad del total.

Los maestros, en su formación durante el diplomado, también como investigadores, vaciaron sus datos en una base que hemos diseñado, bajo el formato de Excel, y la discusión de sus resultados y hallazgos formó parte de dicho proceso, lo cual les permitió no solo conocer aspectos de sus estudiantes que no imaginaban sino también tener una imagen de conjunto del problema de las diversas violencias en la institución. A esto contribuyeron las actividades de sistematización de los resultados de las encuestas en sesiones de consejos técnicos entre los docentes del mismo grado, de los dos turnos, y posteriormente compartidas en plenario, a todo el equipo docente y a las autoridades educativas; al mismo tiempo, estos resultados han sido insumos claves para el diseño conjunto de las intervenciones, como las tutorías entre pares, que durante el mencionado diplomado, estos maestros realizaron en sus grupos de estudiantes para enfrentar algunos de los obstáculos hallados en las aulas, mismas que han tenido el efecto de bajar el índice de reprobación y aumentar los promedios escolares, bajo su guía, y mejorar la convivencia (POUJOL; FRACCHIA, 2017).

Posteriormente al diplomado, con el objeto de profundizar en los primeros hallazgos de los cuestionarios, transformé las bases en Excel en una sola base que transporté al programa Statistical Package for the Social Sciences (SPSS), para la descripción, lo que me llevó a crear categorías de análisis, a partir de los mismos hallazgos y no a priori, es decir, no he partido de categorías preestablecidas de tipos de violencia escolar sino desde las enunciadas por los mismos estudiantes. Esto a su vez, me permitió visualizar aspectos que en la construcción del cuestionario no los habíamos previsto, como la existencia de diversos subgrupos de estudiantes según los efectos que han tenido o no los hechos de violencia. Esto permitió cruzar dichas categorías con sus representaciones o juicios morales al respecto, sus estrategias de respuesta y sus propuestas para transformar los hechos violentos, que se pudo comparar con las realizadas de los maestros participantes.

\section{RESULTADOS Y DISCUSIÓN}




\section{LOS HECHOS VIOLENTOS EN LOS ÁMBITOS COTIDIANOS DE LOS ESTUDIANTES}

La gran mayoría de los estudiantes entrevistados, cuando se realizó la investigación exploratoria, tenía entre 13 y 15 años, aún si el rango de edad era entre 11 y 17 años; $51 \%$ eran hombres, $43 \%$ mujeres y $6 \%$ no se definió al respecto.

Tabla 1. Hechos de violencia por ámbito cotidiano según los estudiantes. Mayo de 2016

\begin{tabular}{lllll}
\hline HAY VIOLENCIAS & EN TU ESCUELA * & EN TU COLONIA & EN TU AULA** & $\begin{array}{l}\text { EN } \\
\text { FAMILIA*** }\end{array}$ \\
\hline SI & $88 \%$ & $76 \%$ & $73 \%$ & $46 \%$ \\
& $(368)$ & $(324)$ & $(304)$ & $(184)$ \\
& & & & \\
\hline NO & $12 \%$ & $24 \%$ & $27 \%$ & $54 \%$ \\
& $(49)$ & $(105)$ & $(110)$ & $(218)$ \\
& & & & \\
\hline
\end{tabular}

Fuente: Elaboración propia, $2019 * 12$ no respondieron (NR); $* * 15 \mathrm{NR} ; * * * 27 \mathrm{NR}$

Observamos que el ámbito más señalado respecto a la existencia de hechos de violencia ha sido la escuela o recinto escolar, seguido por la colonia donde residen y el aula, siendo menor en la familia. (Tabla 1). Sin embargo, los efectos más dolorosos de los hechos mencionados han provenido sobre todo del aula y de la familia, como veremos más adelante.

\section{LOS HECHOS VIOLENTOS EN LAS COLONIAS DE RESIDENCIA $Y$ EN LAS FAMILIAS DE LOS ESTUDIANTES, SU JUICIO MORAL Y SUS EFECTOS}

Antes de profundizar en el ámbito escolar, visualicemos, en primer lugar, el conjunto de hechos violentos, sus efectos y respectivos juicios morales que han enunciado los estudiantes entrevistados en la colonia de residencia y en su familia.

Respecto al ámbito de la colonia de residencia, los estudiantes provenían de 38 colonias, aunque el $70 \%$ residía en diez de ellas, muy cercanas a la colonia donde se asienta la escuela. Los hechos de violencia que han señalado, en orden de mayor a menor intensidad, han sido: peleas y golpes; robos y asaltos; asesinato; violaciones; secuestros y levantones; maltrato; drogadicción y "problemas de violencia en general".
Entre los resultados, no sólo los estudiantes han hecho mención de hechos de violencia, sino que los han nombrado en cada uno de sus diversos ámbitos cotidianos: colonia, familia, escuela y en concreto, también en su aula (Tabla 1), así como los efectos que han tenido y su respectivo criterio moral. 
puedo salir. (ESTUDIANTES ENTREVISTADOS, 2016).

A su vez, el grupo de estudiantes no afectado por la violencia reconocida en su colonia, ha desarrollado estrategias para evitarla como el conocimiento de dónde y cuándo suceden estos hechos; de qué familias cuidarse; de tratar de llevar buena relación con los vecinos y quedarse en casa.

El juicio moral predominante de estos estudiantes es heterónomo, debido a que el ámbito de acuerdos de qué hacer ante estos hechos ha dependido sobre todo de las imposiciones de los padres al respecto sin llegar éstos últimos a trascender de forma explícita alguna estrategia organizativa para la colonia.

En sus familias, los estudiantes que han sufrido hechos de violencia de parte de los adultos, han sido predominantemente las agresiones verbales y físicas, pero también mencionaron como hecho violento la separación entre sus padres. Señalaron la existencia también de hechos de violencia entre adultos: entre papás, tíos, abuelos, sobre todo debido al consumo de alcohol y a la disputa por la herencia familiar.

Han señalado que los principales efectos de la violencia familiar que han resentido han sido a nivel psicológico, en su salud y en provocarles una baja autoestima:

[...] me afecta
psicológicamente, por no
haber convivencia entre
nosotros; cuando peleo con
mi familia nos dejamos de
hablar, me duele mi panza;
no me dan ganas de comer
por los problemas que hay;
me enojo mucho; me
insultan y me bajan mi
autoestima; los insultos, me
siento miserable
(ESTUDIANTES
ENTREVISTADOS, 2016).

En segundo lugar, el efecto más mencionado de la violencia familiar ha sido de tipo físico y doloroso, lo que seguramente ha comportado también efectos psicológicos: "golpes a la persona más débil como a los hijos"; "los papás pegan a sus hijos muy seguido y brutalmente"; "duele"; "me han dejado moretones, me insultan y me hacen sentir mal".

Sin embargo, el hecho más doloroso de todos ha sido la separación física de la familia, que, sin duda, ha involucrado también los demás aspectos:

[...] el que se haya ido (mi madre) porque me sentí triste; me separan de seres queridos; cuando vivía con mis papás siempre peleaba con mi mamá, yo veía lo que pasaba, en toda mi vida siempre me pega, ya he pasado por muchas cosas que a veces recuerdo y me afectan (ESTUDIANTES ENTREVISTADOS, 2016).

Llama la atención que el grupo de estudiantes que se ha dicho no afectado por los hechos violentos en su familia, sin embargo, ha señalado como hecho violento la pelea verbal, mostrando que ésta es ya una práctica totalmente naturalizada. Finalmente, otro grupo de estudiantes ha sentido que en su familia se vive un ambiente tranquilo en donde no hay hechos violentos.

Los hechos violentos en familia refuerzan desde los adultos hacia los menores la moral de la heteronomía, en donde los primeros imponen su ley y debe ser acatada, porque es considerado como el bien y esa es la justicia, sin margen de actuación para los menores. Las relaciones de poder son asimétricas y es grande la indefensión de los estudiantes, que dependen de las decisiones que los adultos toman sobre sus vidas, siendo considerados sus cuerpos como "propiedad" de aquellos.

Cuando estos estudiantes van a su escuela, se llevan a cuestas el conjunto de hechos de violencia desde sus colonias y familias con efectos en sus cuerpos. ¿Y en la escuela, qué sucede?

\section{LOS HECHOS VIOLENTOS EN EL ÁMBITO ESCOLAR, SU JUICIO MORAL Y LOS EFECTOS EN LOS ESTUDIANTES}

El ámbito escolar fue observado desde dos espacios: el del recinto (que incluyó el lugar de entrada y salida de la escuela) y el del aula del estudiante entrevistado. Los hechos de violencia 
registrados entre pares tanto en el recinto como en el de las aulas, han sido, de mayor a menor orden de intensidad: las peleas y golpes, el acoso y el robo. En el recinto, han predominado las peleas a golpes con violencia verbal y en las aulas, el acoso, seguido de las peleas y golpes, y finalmente, del robo.

Las peleas y golpes, siendo cuantitativamente predominantes, son los que más energía han demandado a maestros y autoridades educativas y sin embargo, han sido los que los estudiantes han declarado ser los que menos les ha afectado. Sin embargo, a quienes los han recibido, han señalado efectos, sobre todo a nivel físico ("dejan marcas"; "me duelen"; "salí lastimado") y algunos incluso admitieron provocarlos ("tiré a un compañero al suelo"; "unos a los otros no nos llevamos y discutimos y peleamos").

Para la mayoría, las peleas y golpes han constituido una amenaza $u$ hostigamiento ("querían pelearse conmigo, pero no se les hizo"; "me quiso pegar y no me dejé"; "algunos no hacen nada y empiezan agredir"; "no podemos estar sentados porque llegan ellos a empujarte y te avientan tus cosas").

En otros, han generado sentimientos de impotencia, susto, miedo, incluso ha habido quienes han sido culpados de realizar estos hechos sin pruebas ("no tenía la culpa y aun así me culparon"; "pues, por ver a mis compañeros y no poder hacer nada"; "si, cuando agreden a mis amigos"; "no me gusta ver a las demás personas pelearse").

Sin embargo, a los estudiantes el hecho que más les ha afectado ha sido el robo ("robo de dinero, materiales, celular"; "me robaron mi dinero, mis cosas para la escuela o cosas personales"), mismo que sucede tanto en el recinto como en el aula, ya sea acompañado o no, de peleas o de acoso ("me han robado y pegado"; "me he peleado y me han robado"). El robo les ha afectado en sus relaciones familiares y escolares ("me quedo sin comer y mi mamá me regaña"; "me culpan de agarrar el dinero de mis compañeros, me hacen sentir mal").

En segundo lugar, es el acoso el hecho violento que más les ha afectado, aunque en el aula cuantitativamente, es el más importante. Junto con el robo, son menos visibles que las peleas y golpes, por tanto, son los menos atendidos por los adultos de la institución escolar.

El acoso se ha realizado siempre entre varios compañeros hacia aquellos con determinadas características físicas y psicológicas, incluidas sus preferencias sexuales ("por mi estado físico y por mi forma de ser"; "por mi peso y estatura"; "a los chaparros, gordos, gays los tratan con violencia"); ha incluido la discriminación ("me critican por mi aspecto físico"; "nos afecta a todos porque algunos se unen a los abusadores y otros retiran la mirada"), las burlas, insultos, ofensas, molestias verbales y físicas ("te tiran las cosas";" me ofenden y me hacen de cosas;" "se han burlado de mí "; "le dicen cosas que le lastiman, molestan físicamente"; "casi siempre te insultan verbalmente"). Otras formas del acoso ha sido poner apodos o faltar al respeto, ofender a la familia, esconder las mochilas ("les ponen apodos a todos, a mí también me pusieron uno"; "hablaron mal de mí"; "ofendieron a mi mamá"; "el de las mochilas porque la mía la escondieron en clase").

Los efectos del acoso han sido sobre todo psicológicos y han lastimado la autoestima de los estudiantes ("que me insulten porque baja mi autoestima"; "porque me hacen sentir menos"; "cuando me dicen de cosas y me hacen de menos y cuando me agreden, me dañan psicológicamente").

El efecto psicológico de la baja autoestima, de la anulación de sí mismo atraviesa al conjunto de hechos violentos en los cuerpos de los estudiantes, provengan de los adultos o de sus pares $y$, como veremos en las propuestas que realizan, hay una exigencia por parte de estos adolescentes de que los adultos intervengan para frenar estas situaciones violentas, para que actúen disminuyendo las desigualdades de poder existentes entre pares y con los adultos.

También hay otro grupo de estudiantes que ha reconocido que aún si ellos no han sido objeto directo de violencia en el ámbito escolar, les ha afectado lo que les sucede a sus compañeros, lo cual es un signo de empatía, necesario para poder desencadenar intervenciones que puedan conducir hacia una acción colectiva solidaria ("a mí no, pero se siente feo que hagan bullying a los compañeros"; "a mí no me ha tocado, solo que sí enoja cuando ofenden a alguien que no se puede defender"). 
Finalmente, como en las colonias, ha habido también estudiantes que aún si han reconocido que existen hechos violentos en la escuela, no se han sentido afectados por ellos porque no los han sufrido de manera directa ni en sus pertenencias. Al respecto han desarrollado una serie de estrategias: una de ellas ha consistido en tener que cuidarse de aquellos que provocan los hechos violentos y evitarlos ("no me meto en pleitos ajenos"; "no me molestan, no molesto"; "me alejo de ellos"); o evitar tener la iniciativa directa de los hechos violentos ("yo no me peleo con mis compañeros"; "no fumo, no formo parte de esas peleas, prefiero evitarlas"); han recurrido al desprecio, a la desconfianza ("no son nada mío"; "son problemas de ellos"; "no me interesa") mientras un pequeño grupo incluso ha mantenido una actitud amenazante hacia los demás ("no se meten conmigo"; "jamás me dejaría golpear por un hombre").También existe un pequeño grupo de estudiantes que ha negado la existencia de los hechos violentos en el ámbito escolar y que consideran su relación con los otros muy buena ("me la paso genial en mi escuela"; "me llevo bien con mis compañeros").

Los hechos escolares violentos aunados a la diversidad de juicio moral heterónomo que despiertan en los estudiantes expresan, para la mayoría de ellos, la existencia de un clima escolar amenazante por lo que viven en un estado de alerta permanente para no caer en provocaciones y evitar ser involucrados en las peleas, el acoso o el robo.

En la escuela, como en todo espacio social, también hay grupos de estudiantes que se han tenido que defender y otros, minoritarios, que no han dudado en atacar; futuras investigaciones deberían indagar los procesos sociales que ambos grupos expresan. Aunado a lo que enfrentan también en sus familias y en sus colonias, podríamos decir que existe un impacto importante del clima social violento que atraviesa el país y de un juicio moral que lo justifica en todos los ámbitos de su vida cotidiana.

El conjunto de estos hechos de violencia aquí presentados, sobre todo en el ámbito escolar, nos han llevado a formular la interrogante: ¿qué hacen los adultos de la institución escolar, ya sean maestros $u$ otras autoridades educativas ante ellos?; ¿bajo qué juicio moral se acercan e intentan resolverlos?

\section{RELACIÓN ENTRE ADULTOS Y ESTUDIANTES ANTE HECHOS DE VIOLENCIA EN LA ESCUELA Y SU CORRESPONDIENTE JUICIO MORAL}

Alrededor de dos tercios de los estudiantes ha señalado que los maestros y las diversas autoridades educativas en el plantel han intervenido ante los hechos de violencia en la institución; pero, en segundo lugar, un cuarto de los estudiantes ha sostenido que estos adultos "no han hecho nada" ante estas acciones y finalmente, una minoría incluso, como hemos señalado más arriba, ha negado que existan hechos de violencia en dicho ámbito.

Cuando analizamos las formas de intervención de los adultos ante las acciones violentas, según los estudiantes entrevistados, encontramos que la gran mayoría ha respondido acorde a la normatividad escolar, a través de la aplicación de diferentes tipos de sanciones. Considerando, como hemos señalado más arriba, la correspondencia entre la sanción realizada y el de juicio moral (PIAGET, 1985), hemos podido distinguir que alrededor de dos tercios de las sanciones aplicadas a los estudiantes ante hechos de violencia que han realizado, son de tipo expiatorio y como tal, tienen correspondencia con un juicio moral heterónomo más primitivo, propio del estadio egocéntrico: es cuando la sanción no guarda relación ni con el hecho en sí ni se preocupa en reconocer las intencionalidades de los autores involucrados, lo que hace innecesaria una investigación sobre estos hechos violentos. Expresa una responsabilidad objetiva, basada en un concepto de justicia retributiva (PIAGET, 1985).

Estas sanciones de tipo expiatorio se refieren específicamente a reportes, citatorios 0 el "acompañamiento" obligado de los padres a asistir con sus hijos hasta por cuatro días en sus aulas:

[...] nos mandaron a trabajo social a todos y nos dijeron que si reincidíamos nos cambiaban de turno; ir a trabajo social, escribir en una hoja, quien creíamos que era o llamar a la policía; citatorio y acompañamiento por 3 y 4 días; solo aplicó un 
reporte y ya (ESTUDIANTES ENTREVISTADOS, 2016).

Finalmente, hay intervenciones que asumen solamente las autoridades educativas como la "expulsión" ("han expulsado a los responsables 0 han puesto citatorios 0 acompañamiento a estos estudiantes"; "cuando saben quién es, lo expulsan"); "cambio de turno o de grupo y suspensión" del estudiante ("los separaron y los suspendieron"; "los pasan a la tarde o los hacen doblar turno"; "cambiar de salón al que molesta") y la realización de la "vigilancia," que incluye a docentes e incluso a policías ("los maestros empezaron a cuidar la escuela a la hora de la salida"; "han expulsado a niños y cuando hay peleas mandan a la patrulla"; "la directora lo metió a la cárcel"). (Tabla 2).

Tabla 2. Tipo de sanciones de los adultos a estudiantes responsables de hechos violentos entre pares, según los estudiantes. Mayo de 2016

\begin{tabular}{llllll}
\hline \multirow{2}{*}{$\begin{array}{l}\text { TIPO DE SANCIONES DE } \\
\text { ADULTOS }\end{array}$} & LOS & EN EL RECINTO & EN EL AULA & \\
\cline { 2 - 6 } & & Estudiantes & Porcentaje & Estudiantes & Porcentaje \\
\hline $\begin{array}{l}\text { EXPIATORIAS: Sanciones y castigos, } \\
\text { expulsión, suspensión, cambio de }\end{array}$ & 189 & $68 \%$ & 145 & $65 \%$ \\
turno, de grupo, reporte, citatorio y & & & & \\
acompañamiento de los padres & & & & \\
\hline $\begin{array}{l}\text { DE RECIPROCIDAD: Diálogo } \\
\text { regaño, vigilancia docente }\end{array}$ & 0 & 91 & $32 \%$ & 79 & \\
policíaca & & $\mathbf{2 8 0}$ & $\mathbf{1 0 0 \%}$ & $\mathbf{2 2 4}$ & $\mathbf{1 0 0 \%}$ \\
\hline TOTAL & & & & \\
\hline
\end{tabular}

Fuente: Elaboración propia, 2018.

Sin embargo, alrededor de un tercio de las sanciones aplicadas por los adultos de la institución escolar hacia los estudiantes que han realizado algún hecho de violencia podrían ser consideradas "sanciones por reciprocidad", que aún si todavía están en correspondencia con un juicio moral heterónomo, están en una fase más cercana al estadio hacia la cooperación naciente (PIAGET, 1985) como son el "diálogo o regaño", en que los maestros escuchan a los estudiantes ("pues cuando se pelean hablan con esas personas y ellos ya saben qué hacen con ellas"; "les dijo que no está bien robar"), tratando de conocer la intencionalidad de los involucrados y que la sanción tenga correspondencia con la falta. (Tabla 2).

Ambos tipos de sanciones expresan una responsabilidad objetiva, basada en un concepto de justicia retributiva (PIAGET, 1985). De hecho, hemos identificado una concatenación de responsabilidades delegadas por los adultos que, al final de cuentas, acaban todas recayendo sobre los estudiantes. Es decir, cuando los hechos violentos no lo resuelven en aula, a través del segundo grupo de sanciones, los docentes acuden a las diversas autoridades escolares y éstas a su vez, a los padres de familia.

Es interesante destacar que ante la pregunta expresa de qué violencias habrían recibido en la escuela, ningún(a) estudiante ha señalado hechos de violencia de los adultos hacia ellos ni viceversa; sin embargo, ante la interrogante acerca de qué han hecho los adultos ante las formas de violencia señaladas por ellos, se desprenden estas acciones que bien podrían ser catalogadas como violencia pero que ciertamente, los estudiantes no lo conceptualizan de esta manera sino que, gracias a su prevaleciente juicio moral heterónomo, conciben que los que los adultos han realizado es lo correcto y que ellos mismos lo realizarían.

Aun con este gradiente de diferencia en los tipos de sanciones, en realidad, la práctica o acciones de los adultos de los ámbitos escolar y familiar, refuerzan la desigualdad de poder respecto a los estudiantes, así como la existente entre pares, a través de la imposición de éstas con efectos en sus cuerpos. 
Al analizar las respuestas de los estudiantes entrevistados respecto a los tipos de intervenciones adultas escolares ante los hechos violentos entre pares hemos descubierto que cada tipo de hecho identificado recibe diferentes intervenciones. Por ejemplo, en el caso de las peleas y golpes ha predominado la aplicación de sanciones expiatorias, más específicamente, reporte, citatorio y acompañamiento de los padres, seguido por la inacción de autoridades y maestros ("no hacen nada").

En cambio, esta inacción es la que ha predominado en los hechos de acoso y de robo, que son los que más afectan a los estudiantes. En segundo lugar, para el acoso, ha prevalecido el "diálogo o regaño" hacia los estudiantes o a la aplicación de reporte, citatorio y acompañamiento y para el robo, las demás sanciones: reporte, citatorio y acompañamiento:

[...] nunca han hecho nada, desafortunadamente nada, solo hacen algo cuando ya ven que algún alumno se está muriendo; nada, porque si no va al baño, se pone en el celular o a platicar con otros maestros; No hizo nada porque nadie dice nada; Nada, nunca se enteran (ESTUDIANTES ENTREVISTADOS, 2016).

Más específicamente, los estudiantes opinan que en sus aulas, los maestros no han hecho nada porque no se han enterado debido a que los hechos violentos han ocurrido, en general, cuando no han estado presentes.

Las inacciones de los maestros reflejan el más alto grado de heteronomía y desinterés hacia el otro. Como hemos señalado, una gran parte de los hechos violentos en la escuela ha sucedido por ausencia u omisión de los adultos -maestros y autoridades- en un espacio escolar en donde la responsabilidad de los hechos violentos es atribuida a la familia y en particular a los estudiantes, mismos que, cuando ha habido una intervención, ha sido coercitiva predominantemente, reforzando la moral de la heteronomía.

El conjunto de los hechos escolares violentos y las formas en que son enfrentados por los maestros y autoridades educativas, ha tenido, para los estudiantes, un impacto colectivo, afectando al clima escolar y al aprendizaje, en primer lugar, en la relación entre pares:

[...] hacen que se pierda la comunicación; nos afectan al salón porque nos separamos $y$ nos peleamos; normalmente hacen que las pautas de convivencia se rompan, al igual que la amistad; afecta mucho eso en el salón, involucran a los que no hacen bullying; si, el que la tutora me haya corrido porque yo quería estar con mis amigos; nos sacan del salón y no terminamos los trabajos; quitan tiempo y trabajo en clase; la tutora se enojó y nos aventaba las [tareas de]habilidades de matemáticas (ESTUDIANTES ENTREVISTADOS, 2016).

En segundo lugar, entre maestros $y$ estudiantes, ya que parece ser bastante común que cuando los adultos se han enterado de estos hechos violentos en el aula, han procedido a castigar todo el grupo:

[...] nos regañan a todo el salón; nos dejan sin recreo; cancelan las tardeadas; la directora regaña a todos; pagamos las consecuencias; no te dejan concentrar en lo que estás haciendo (ESTUDIANTES ENTREVISTADOS, 2016).

De este modo, los adultos en la escuela objeto de estudio han actuado -o dejado de actuarante los hechos de violencia de sus estudiantes desde un juicio moral heterónomo basado en la aplicación más de sanciones expiatorias que de reciprocidad basado en parte en el cumplimiento de una normatividad que incluso ellos mismos han reconocido como ya no acorde a los tipos de violencias que existen o a la indolencia, a la inacción, reforzando el clima de violencia y de amenaza que viven los estudiantes. 
Destaca, como parte del juicio moral heterónomo, la falta de conciencia de que ciertos comportamientos de los adultos hacia ellos, que lo han sabido describir en detalle aunado a sus efectos en ellos mismos y en el propio proceso de aprendizaje, constituyen hechos de violencia.

\section{LAS PROPUESTAS DE LOS ESTUDIANTES Y DE LOS MAESTROS ANTE LOS HECHOS DE VIOLENCIA ESCOLAR EN CORRESPONDENCIA A SU JUICIO MORAL}

Para finalizar, conscientes de la existencia de hechos violentos escolares y su relación con un predominante juicio moral heterónomo, hemos pasado a analizar las respuestas de los 32 docentes participantes en el diplomado y de dos tercios de los estudiantes entrevistados a la pregunta: ¿tú que hubieras hecho ante los hechos de violencia en tu aula?

Mientras que los docentes han reiterado en su respuesta lo que realizan ante dichos hechos, como hemos descrito en el apartado más arriba, el $53 \%$ de los estudiantes también ha sugerido realizar las mismas acciones que los adultos de la institución escolar, lo que muestra la internalización del sistema normativo escolar, predominantemente coercitivo, propio del juicio heterónomo. Incluso, la proporción de los estudiantes ha sido mayor respecto a los docentes, en sugerir las sanciones expiatorias más dolorosas: la expulsión de sus compañeros ("los niños deberían ser castigados con la expulsión para meterles miedo"; "deberían ser castigadas horriblemente, pero con esta corrupción, las apoyan"), y en la necesidad de incrementar la vigilancia y la seguridad, incluso policíaca ("más vigilancia o mantener a los agresores fuera de la escuela"; "debería de haber más seguridad": policía o seguridad privada").Así, en la gran mayoría de los estudiantes entrevistados pesa el mismo juicio moral heterónomo que acepta las formas de enfrentar cada hecho como estipulado por los adultos y éstos, por la normatividad escolar, sin cuestionamiento al respecto. (Ver Tabla 3).

Tabla 3. Propuestas de docentes y estudiantes para enfrentar hechos violentos en aula. Mayo de 2016

\begin{tabular}{llll} 
PROPUESTAS & & DOCENTES & ESTUDIANTES \\
\hline SANCIONES EXPIATORIAS & $\begin{array}{l}\text { Reporte, Citatorio, } \\
\text { Acompañamiento }\end{array}$ & $45 \%$ & $30 \%$ \\
\cline { 2 - 4 } & & & \\
\cline { 2 - 4 } & Sanciones en general & $17 \%$ & $13 \%$ \\
\cline { 2 - 4 } & Expulsión/Suspensión & $3 \%$ & $13 \%$ \\
\hline SANCIONES POR RECIPROCIDAD & Vigilancia & $2 \%$ & $15 \%$ \\
\cline { 2 - 4 } & Diálogo & $33 \%$ & $29 \%$ \\
\hline TOTAL & & $100 \%$ & $100 \%$
\end{tabular}

Fuente: Elaboración propia,2018

Peor aún, ha habido estudiantes que no solo pugnan por la moral heterónoma más primitiva sino que, abiertamente han defendido la agresión como el modo de dirimir las diferencias:

$$
\begin{aligned}
& \text { [...] hacerle (al compañero) } \\
& \text { lo mismo (que el maestro) } \\
& \text { pero peor; yo hubiera hecho } \\
& \text { lo mismo, llamado a la } \\
& \text { policía y hablado con sus } \\
& \text { padres; mandarlos golpear; } \\
& \text { pelear más; romperle la cara } \\
& \text { al otro; traerlas y pegarles; } \\
& \text { pienso en suicidio. } \\
& \text { (ESTUDIANTES } \\
& \text { ENTREVISTADOS, 2016). }
\end{aligned}
$$

A su vez, una minoría de estudiantes no realizó propuestas ya que ha sostenido, con una visión fatalista que ante la violencia: "no hay nada que hacer" $u$ otros, que no han sido víctimas directas de ningún hecho de violencia, han decidido que es mejor no intervenir y hacen caso omiso a lo que sucede, como estrategia o forma de sobrevivir a la situación de violencia, reforzando la visión heterónoma de los adultos que lo rodean ("ha habido muchas peleas, pero no son problemas míos, así que me da igual"; "nada, no es mi asunto").

La mayoría de los estudiantes se encuentren en alerta permanente, ante un 
ambiente amenazador donde solo quedan las propias fuerzas para defenderse. De hecho, una característica del juicio moral heterónomo es la ausencia de una conciencia acerca de la dimensión social de la violencia, hay una concepción inmanente de la misma, como si ésta fuera un factor presente e inevitable de la vida social, que afecta a nivel personal o familiar sólo si se es víctima directa de ella.

Sin embargo, también existe, a pesar de ser minoritario, otro grupo de estudiantes que ha sugerido ante los hechos de violencia que han reconocido, anteponer el diálogo y la escucha entre docentes y estudiantes como prioridad, ante los hechos violentos, estableciendo condiciones que favorecerían la transición hacia un comportamiento cooperativo:

[...] pues, que hablen y dejen hablar a los alumnos, no solo regañarlos sino tratar de saber por qué lo hicieron; es necesario que tomen otras medidas, que nos crean $y$ que nos brinden más su apoyo; es necesario tomar otras medidas y hablar con los niños que sufren violencia (ESTUDIANTES ENTREVISTADOS, 2016).

Algunos estudiantes además han realizado propuestas que ni siquiera fueron esbozadas por los adultos ("reponer lo robado") y han propuesto adoptar estrategias para disminuir la indefensión existente: "hay que estar precavidos y además estar conscientes de las causas y consecuencias de lo que hacemos, así como favorecer comportamientos propios entre iguales", que es la ley de la verdadera cooperación (PIAGET,1985), además de : "ayudar a mis compañeros"; "llevarme mejor con mis amigos"; "poder ayudar en no generar más problema."

Son más los estudiantes que además han sugerido como prioridad, que los docentes pongan atención a los estudiantes para evitar los hechos de violencia y que los resuelvan:

[...] los profesores a veces no hacen nada y quisiera que nos pusieran más atención y que hubiera actividades dentro de la escuela para prevenir y evitar violencia; hay niños que sufren pero los maestros no se dan cuenta; pues joder, que los maestros tengan más cuidado porque la mayoría pasa cuando salen al baño o cosas así; que si los profesores pusieran más atención y que en las clases no estén con el celular, se darían cuenta ; que ya le paren y que se pongan hacer su trabajo y que en verdad entreguen el corazón (ESTUDIANTES ENTREVISTADOS, 2016).

Con claridad, tenemos así dos grandes grupos de estudiantes con juicios morales heterónomos, de diferente grado. Si se refuerzan intervenciones en forma de trabajos conjuntos entre aquellos que pugna por un juicio moral más cercano a una moral de cooperación, aún si son minoría, aunado a una labor de acompañamiento y de formación de maestros y autoridades educativas al respecto, se podría reducir con creces la indefensión social de la que se caracteriza el entramado socioescolar y se humanizarían las relaciones sociales. Lo que contribuiría a resquebrajar el estado de heteronomía imperante y obtener una convivencia que permita crecer hacia la cooperación y autonomía, tan necesarias para la apropiación del aprendizaje y para el cuidado de sí mismo y colectivo.

\section{CONCLUSIONES}

Este estudio exploratorio nos permitió, junto con los maestros de la secundaria objeto de estudio, visualizar el conjunto de hechos violentos que sus estudiantes reconocieron en sus colonias de residencia, en sus familias y en el ámbito escolar, así como los efectos que estos han tenido en sus cuerpos, siendo predominantes sentirse bajo amenaza permanente $y$ tener baja su autoestima.

El juicio moral heterónomo es el que ha caracterizado a los adultos que se vinculan con los estudiantes, y a ellos mismos, debido a que el margen de prácticas de común acuerdo es casi inexistente para enfrentar los hechos de violencia entre pares. Los adultos les imponen la 
normatividad, ya sea la recibida como costumbre en el ámbito familiar o la escolar. Ante la desobediencia, al infringir la normatividad con la realización de hechos violentos, los estudiantes reciben sanciones, en diferentes grados, en correspondencia con dicho juicio moral. Al constituirse como autoridad los adultos, las sanciones son aceptadas por ser consideradas el bien y la justicia y refuerzan el círculo de violencia, en consonancia, con el orden social. Más aún con un segundo modo en que los adultos reaccionan ante los hechos violentos escolares: su inacción, siendo éste un grado extremo de la heteronomía.

Estos tipos de acciones de los adultos refuerzan la desigualdad de poder respecto a los estudiantes, y se constituyen en formas de evadir sus responsabilidades, descargándoselas a los propios estudiantes e incluso a sus padres, además de haber afectado, en palabras de los adolescentes, al aprendizaje y genera un clima escolar de amenaza permanente, donde solo quedan las propias fuerzas para defenderse a la mayoría o agredir, a un grupo minoritario.

De hecho, una característica del juicio moral heterónomo es la ausencia de una conciencia acerca de la dimensión social de la violencia, hay una concepción inmanente de la misma, como si ésta fuera un factor presente e inevitable de la vida social, que afecta a nivel personal o familiar sólo si se es víctima directa de ella. Así, el sistema normativo

$$
\begin{aligned}
& \text { [...] crea y mantiene una } \\
& \text { territorialidad social que } \\
& \text { permite el ejercicio y } \\
& \text { mantenimiento de una } \\
& \text { heteronomía impune y } \\
& \text { despótica que produce y } \\
& \text { reproduce de forma } \\
& \text { ampliada un proceso de } \\
& \text { desigualdad social entre } \\
& \text { individuos, relacionado a } \\
& \text { cómo participan en el } \\
& \text { proceso de la génesis } \\
& \text { normativa. Unos "armados } \\
& \text { para la agresión" y otros } \\
& \text { "desarmados para la } \\
& \text { agresión" (MARín, 2005, p. } \\
& \text { 20). }
\end{aligned}
$$

Uno de los hallazgos acerca del juicio moral heterónomo en los estudiantes lo hemos obtenido al analizar sus propuestas de acción ante hechos violentos: la gran mayoría ha argumentado que haría exactamente lo que hacen los maestros, incluso recurrirían más frecuentemente a la expulsión o suspensión de los compañeros que han provocado los hechos violentos e incrementarían la vigilancia incluida la policíaca.

Sin embargo, aquellos que han señalado la inacción de los adultos, demandaban como prioridad, que los maestros estén presentes en el aula siempre y que les pongan atención, para prevenir o resolver dichos hechos. También ha habido algunos estudiantes que han esbozado propuestas que ni siquiera fueron sugeridas por los adultos ("reponer lo robado") así como estrategias para disminuir la indefensión existente, como "favorecer comportamientos propios entre iguales", que es la ley de la verdadera cooperación (Piaget,1985).

Si se realizan intervenciones en forma de trabajos conjuntos entre este grupo de estudiantes que pugna por un juicio moral más cercano a una moral de cooperación, aún si son minoría, aunado a una labor de acompañamiento y de formación de maestros y autoridades educativas al respecto, se podría reducir con creces la indefensión social que caracteriza el entramado socioescolar y se humanizarían las relaciones sociales. Lo que contribuiría a resquebrajar el estado de heteronomía imperante y obtener una convivencia que permita crecer hacia la cooperación y autonomía, tan necesarias para la apropiación del aprendizaje. Estas intervenciones deberían favorecer la interacción de la escuela con otros servicios socioeducativos del territorio para enfrentar la compleja realidad que la rebasa, misma que nos remite a la que atraviesa el país, que se expresa sobre todo en un juicio moral que justifica o refuerza la violencia con su realización o la amenaza permanente o la inacción e indiferencia hacia quienes son víctimas, en cualquiera de los ámbitos de la vida cotidiana. Pero también hay quienes luchan para tratar de revertirla.

Este estudio constituye una propuesta de considerar los cuerpos de los estudiantes en su totalidad en relación a los hechos de violencia existentes en su cotidiano y no se limita a buscar una tipología de hechos de violencia entre pares sino que a partir de éstos, desde una concepción de un entramado socioescolar de relaciones sociales, se ha analizado también la actuación de los adultos 
ante dichos hechos, resultando otras fuentes de violencia, como expresión del tipo de juicio moral heterónomo en dichas relaciones sociales. Una limitante que rebasa este artículo ha sido no incluir los hechos de violencias que también existen entre adultos, que emergieron a lo largo del diplomado ofertado y que también impactan el clima escolar.

\section{REFERENCIAS}

CASTILLO, C.; PACHECO, M. Perfil del maltrato (Bullying) entre estudiantes de Secundaria en la Ciudad de Mérida, Yucatán. Revista Mexicana de Investigación Educativa, México, v. 13, n. 38, p. 825-842, 2008.

ELÍAS, N. El proceso de la civilización. Investigaciones sociogenéticas y psicogenéticas. México: Fondo de Cultura Económica, 1989.

FRACCHIA, M. Propuesta de un enfoque basado en aportes sociopsicogenéticos para la formación en investigación-intervención sobre la relación entre violencia escolar y violencia social. En: VELÁZQUEZ, G. El paradigma de la complejidad y la investigación de los problemas sociales, educativos y culturales del siglo XXI. México: Universidad Pedagógica Nacional, 2018.

FURLAN, A. Convivencia, disciplina y violencia en las escuelas. Revista Mexicana de Investigación Educativa. México: COMIE, 2003.

FURLAN, A. Reflexiones sobre la violencia en las escuelas. México: Siglo XXI, 2013.

GARCÍA SALORD, S. "La violencia simbólica: aportación de Pierre Bourdieu para comprender las formas sutiles e inadvertidas de dominación". En: FURLÁN, A. Reflexiones sobre la violencia en las escuelas. México: Siglo XXI, 2012, p. 114-143.

GUTIÉRREZ, A. "Poder, hábitus y representaciones: recorrido por el concepto de violencia simbólica en Pierre Bourdieu". Revista Complutense de la Educación, v. 15, p. 289-300, 2004.

KLOSTER, K.; FRACCHIA, M. El costo humano en la construcción de los dominios territoriales. En: KLOSTER, K. (Coord.) Conflictividad y violencias en
América Latina. Ciudad de México: UACM, 2017. p. 229-264.

MALDONADO, S. La escuela como territorio de intervención política. Buenos Aires: Gráfica Alsina,2004.

MARÍn, J. C. Prólogo. Pensar en voz alta. En: MULERAS, E. Conocimiento y sociedad. Buenos Aires: Ed. P.I.Ca.So., 2005, p.13-25.

MARÍN, J. C. Conversaciones sobre el poder. Buenos Aires: Universidad de Buenos Aires, 1995.

LÓPEZ, M.; SAÑUDO, L.; MAGGI, R. (Coords). Investigaciones sobre la investigación educativa 2002-2011. México: ANUIES, Dirección de Medios Editoriales: Consejo Mexicano de Investigación Educativa. (Colección Estados del Conocimiento), 2013.

OLWEUS, D. Conductas de acoso y amenaza entre escolares. Madrid: Morata, 1998.

OVIEDO, D.; FRACCHA, M. Estado de la cuestión en torno a las violencias en las escuelas. Revista Educación, Formación e Investigación, v. 4, n. 7, diciembre de 2018.

PIAGET, J. Introducción a la epistemología genética: la explicación sociológica - Tomo III. Buenos Aires: Paidós, 1975.

PIAGET, J. El criterio moral en el niño. México, Ed. Roca,1985.

POUJOL, G.; FRACCHIA, M. Efectos sociales y educativos de la violencia escolar en una secundaria pública en Morelos. Revista Polisemia, Bogotá, n. 22, p. 91-105, 2017.

SAUCEDO, C.; GUZMÁN, C. La investigación sobre la violencia escolar en México: tendencias, tensiones y desafíos. Revista Cultura y Representaciones Sociales, v. 12, n. 24, p. 213-245, 2018. Disponible en:

http://www.culturayrs.org.mx/index.php/CRS/artic le/view/472 
SPOSITO, M. Um breve equilíbrio da pesquisa sobre violencia escolar no Brasil. Educação e Pesquisa, São Paulo, v. 27, n. 1, p. 87-103, 2001. https://doi.org/10.1590/S1517-

$\underline{97022001000100007}$ 